\title{
Prevalence of blood borne viruses in IVF: an audit of a fertility Centre
}

\author{
Michael B Yakass ${ }^{1}$, Bryan J Woodward ${ }^{2}$, Mary A Otoo ${ }^{1}$, Edem K Hiadzi ${ }^{1}$ \\ ${ }^{1}$ Assisted Conception Unit, Lister Hospital \& Fertility Centre, Accra, Ghana \\ ${ }^{2}$ IVF Consultancy Services, Leicester, UK
}

\begin{abstract}
Objective: The rate of infertility continues to be on the increase in the developing world. Similarly, the rates of blood-borne viral infections (BBVs) such as Human Immunodeficiency Virus (HIV), Hepatitis B virus (HBV) and Hepatitis C virus (HCV) are also on this rise. In 2014, the World Health Organization (WHO) quoted prevalences of $1.5 \%$ (HIV), $15 \%$ (HBV) $1.3-8.4 \%$ (HCV) in the Ghanaian general population. It has been reported that BBVs can adversely affect male fertility, specifically sperm count and progressive motility. The aim of this study was to evaluate the prevalence of BBVs in people with infertility attending an IVF clinic and whether or not BBVs impacted on sperm parameters.

Methods: A retrospective cohort study at a private fertility center in Accra, Ghana. We had 229 recruited couples assayed for HBV, HCV and HIV. Sperm parameters of the male partners were also assessed. The analysis performed included student t-test and Fisher's exact test.

Results: We found prevalence rates of $1.7 \%$ (HIV), $7.9 \%$ (HBV) and $0.4 \%(\mathrm{HCV})$, which is similar to what has already been reported in the Ghanaian community. There was no significant difference between BBV positive and negative subjects for sperm count (13.6 million/ml vs. 17.7 million/ $\mathrm{ml}, P=0.0599)$, percentage of progressive motility $(26 \%$ vs. $30 \%, P=0.2129$ ), percentage of normal forms (3\% vs. $3 \%, P=0.0617)$ and clinical pregnancy rates per embryo transfer $(36.1 \%$ vs $34.9 \%, P=0.5)$ between BBV positive and BBV negative subjects, respectively.

Conclusion: There is a similar prevalence of BBVs in sub-fertile couples and the general Ghanaian population. However, no detrimental effect has been reported for sperm parameters on grounds of BBV infectivity of the male partner.
\end{abstract}

Keywords: Hepatitis B, Hepatitis C, HIV, sperm quality, IVF

\section{INTRODUCTION}

Worldwide more than 70 million, or $10 \%$ (Boivin et al., 2007) of couples, suffer from infertility, with a high proportion living in developing countries (Ombelet et al., 2008). The inability to have children can have negative emotional, psychological and social impacts on the lives of these people (Ombelet et al., 2008; Rouchou, 2013). In general, secondary infertility has been shown to dominate over primary infertility in most developing countries, and this is chiefly a result of improperly treated sexually transmitted infections (STIs), resulting in pelvic inflammatory disease (PID) (Larsen et al., 2006; Elussein et al., 2008).

It is estimated that 40 million people worldwide are living with HIV/AIDS and approximately two thirds of those live in sub-Saharan Africa (WHO, 2015). The World Health Organization (WHO) quotes a prevalence of $1.1-2.0 \%$ in the Ghanaian general population (WHO, 2015). The national sero-prevalence of HIV was estimated to be $1.5 \%$ in 2013 by the national AIDS control program in Ghana (Ghana Health Service, 2008).

HIV-infected people were initially discouraged from starting a family (Savasi et al., 2013). However, with the introduction of antiretroviral therapies, life expectancies and the quality of life has dramatically improved and many infected people are now thinking of starting a family, usually via assisted reproductive technology (ART) (Savasi et al., 2013).

Several studies have documented reduced fecundity in HIV-infected individuals compared to uninfected people (Glynn et al., 2000, Brocklehurst \& French, 1998). On the other hand, marital instability and polygamy, secondary to infertility, may in turn increase the spread of HIV-1 infection (Ombelet et al., 2008).

The prevalence of chronic Hepatitis B virus (HBV) infection varies widely according to geographical area. Sub-Saharan Africa is endemic in HBV with an estimated 5-25\% being chronic carriers (Candotti et al., 2007). HBV prevalence in Ghana has been estimated to be around 15\% (Ghana Health Service, 2008).

The prevalence of the Hepatitis C Virus (HCV) has been reported to be $>1 \%$ in southern African countries, 1.7 $27.5 \%$ in central Africa and $1.4-7 \%$ in West and East Africa (Candotti et al., 2003). The estimated serum-prevalence of $\mathrm{HCV}$ is $1.3-8.4 \%$ among blood donors in Ghana (Ampofo et al., 2002).

In general, BBV infections have been shown to contribute to male infertility either by direct toxic effects on cells in the male reproductive tract, and/or indirectly by causing a local inflammatory or immunological reaction (Zhou et al., 2011). HBV infection has been reported to increase chromosomal instability in sperm and impair overall sperm quality (Huang et al., 2003, Huang et al., 2002). Furthermore, HBV has been linked to decreased sperm motility (Lorusso et al., 2010). However, other studies have reported no significant difference in sperm quality between HBV -serum-positive and -negative men (Zhou et al., 2011). Reduced implantation and pregnancy rates have also been shown following IVF treatment for people with HBV compared to age-matched controls (Pirwany et al., 2004).

The handling of potentially BBV-infected body fluids, gametes or embryos is a risk to healthcare professionals, such as physicians, nurses and embryologists. In addition, uninfected couples being treated at the same time may be at risk of nosocomial contamination (Lesourd et al., 2000). This is why strict adherence to the testing of all people seeking ART for HIV, HBV and HCV is mandatory (The Commission of the European Communities, 2006; Practice Committee of American Society for Reproductive \& Practice Committee of Society for Assisted Reproductive, 2008).

The aim of the current study was to calculate the BBV prevalence in people seeking ART at a private fertility clinic in Accra, Ghana. We also investigated if BBVs have any effect on sperm parameters. 


\section{MATERIALS AND METHODS}

Subjects were recruited between March 2013 and July 2015. Participating subjects signed consent forms to participate in the study, which was approved by the hospital's ethics and practice committee.

Two hundred and twenty nine (229) heterosexual couples were recruited for this study, having complete viral screening results (HIV, HBV, HCV). Recipients of donor gametes (either sperm or oocyte) were included, provided the other gamete originated from a BBV-infected partner. Patients receiving frozen embryo transfers were excluded.

For BBV analysis, $5 \mathrm{ml}$ blood was collected by venipucture into serum separator tubes and centrifuged at $500 \mathrm{~g}$ for 5 minutes to separate the serum from cells. HBsAg, Anti-HIV 1 and 2 and HCV were determined from the serum with rapid diagnostics kits (Tellmefast, Biocan Diagnostics Inc, Canada). Quality control checks were performed daily before running assays.

The IVF stimulation protocol was as follows; down-regulation was achieved with 0.5 units of buserelin administered from Day 2 of the menstrual cycle till HCG administration. An ultrasound scan was performed between 14 - 21 days after starting buserelin injections to assess ovarian status and endometrial thickness. When down regulation was achieved, controlled ovarian stimulation (COS) was initiated alongside the buserelin administration. For the COS, 225 - 400 IU of recombinant FSH (Fostimon, IBSA, Switzerland) was administered daily for $7-10$ days. An ultrasound scan was performed to assess follicular response between 5 - 7 days of COS and dosage adjusted accordingly when required. HCG (10,000 IU) (Choriomon, IBSA, Switzerland) was administered when the leading follicle was at least $18 \mathrm{~mm}$. Ultrasound-guided follicle aspiration was performed using a $17 \mathrm{G}$ Cook aspiration needle (Cook, Australia) 36 hours after the HCG injection.

Semen samples produced on the day of the IVF/ ICSI procedures were analyzed according the latest WHO laboratory manual for the examination and processing of human semen (Cooper et al., 2010).

The semen was prepared by the density gradient technique of sperm preparation. $1 \mathrm{ml} 40 \%$ gradient was gently over-layered onto $1 \mathrm{ml} 80 \%$ gradient (Global, IVF Online, Denmark) and warmed in the incubator set to $37^{\circ} \mathrm{C}$ for 30 minutes. $1 \mathrm{ml}$ of the semen was gently over-layered on the $40 \%$ gradient and centrifuged at $300 \mathrm{~g}$ for $10 \mathrm{~min}-$ utes. The supernatant was gently aspirated and discarded. About $0.3 \mathrm{ml}$ of the remaining pellet was aspirated and transferred into $3 \mathrm{ml}$ of AllGrad sperm washing solution (Global, IVF Online, Denmark) and centrifuged at $300 \mathrm{~g}$ for 5 minutes. The supernatant was gently aspirated and discarded. A sperm count and motility assessment was then performed on the washed pellet using a sterile technique. This pellet was kept for use in the IVF procedure.

Semen samples from BBV infected males were also processed using the density gradient centrifugation method with three gradient layers $90 \%, 70 \%$ and $40 \%$, under a sterile technique. The removal of the supernatant at each step prior to transfer of the pellet helped minimize any viral transmission (Zamora et al., 2016).

Developing embryos from BBV-positive couples were cultured in separate gassed incubators (5\% CO2, $6 \% 02$ and $89 \%$ nitrogen, BOC, UK) from BBV-negative couples, to eliminate any risk of cross-contamination as per best practice (Magli et al., 2008).

A pregnancy test was performed on the serum of the female partners two weeks after the embryos were transferred.

Results were expressed as mean \pm SEM or mean (range). The data was analysed using the Graph Pad Prism - version 5 (Graph Pad Software, San Diego California). Student t-test and Fisher's exact test were used to as- sess significance. Statistical significance was set at $P<0.05$

\section{RESULTS}

Twenty-three (23) couples had repeat IVF treatments. One (1) female partner and four (4) male partners tested positive for HBsAg in both cycles. Two (2) male partners who tested negative at the first IVF cycle tested positive for HBsAg in the second, despite the advice and the availability of the hepatitis B vaccine at the Public Health Unit of the hospital. The time interval between both cycles was twelve (12) months for one male and 21 months for the other. Primary infertility was dominant over secondary infertility in our study population (Table 1 ).

HBV prevalence was higher in the study population compared to their HIV and HCV infected counterparts. More men were significantly infected with the HBV than women $(P=0.0027)$. The study did not find any significant difference in semen quality, i.e. sperm count, percentage progressive motility and percentage normal forms of BBV positive and BBV negative males. However, there was a trend for mean sperm count and percentage progressive motility to be higher in the BBV-negative males, although this was not significantly different from BBV-positive males (Table 2).

On account of the high prevalence of HBV, the effect of this virus on semen was assessed separately (Table 3 ). However, we found no significant difference in semen quality between HBV-infected males and those not infected.

There was no statistical difference in semen quality when HIV infected males were compared to their HIV uninfected males (Table 4). All 5 males and the 3 females infected by the HIV were on the highly active anti-retroviral therapy (HAART).

There was only 1 male infected with the HCV hence comparative analysis of semen quality between HCV positive and HCV negative males could not be performed due to small numbers.

We did not find any significant difference for clinical pregnancy rates between BBV-infected and uninfected couples (Figure 1). Interestingly, BBV-infected women had slightly higher pregnancy rates than those without BBV infection (36.1\% vs $34.9 \%, P=0.5000,1$-tailed).

\section{DISCUSSION}

BBV (HIV, HBV and HCV) prevalence in our study population was similar to that found in other studies (Duda et al., 2005). Techniques, such as the density gradient sperm preparation, have been shown to significantly reduce the risk of transmission of viral infection from parent to offspring, especially if the male is infected (Zafer et al., 2016). With this, one might consider that BBV prevalence might be higher in an IVF population than in the general population, since infected men can take advantage of such procedures to prevent the risk of transmitting the virus to partners and offspring. However, it is possible that BBV-infected couples are still unaware of the benefits of such ART techniques, and as such, have not taken the opportunity it offers them to procreate without the risk of viral transmission to their offspring. It is also possible that they are aware of these benefits but are unable to pay for such services.

It has been reported that male partners of infertile heterosexual relationships may have extra-marital affairs in their quest to achieve pregnancy (Ombelet et al., 2008). As such, they are more likely not to use any physical barrier contraception such as condoms and, as a result, are more prone to contract sexually transmitted infections such as BBVs (Ombelet et al., 2008). This is evident in the current study, since more males were infected with BBV than their female counterparts (Table 2). Two male patients tested positive for HBsAg on their second attempt at IVF/ICSI, 
Table 1. Demographics of the general populationmigration pattern.

\begin{tabular}{|c|c|c|c|}
\hline Parameters & BBV Positive & BBV Negative & $P$ - value \\
\hline $\begin{array}{l}\text { Age }(y) \\
\text {-Males } \\
\text {-Females }\end{array}$ & $\begin{array}{l}40(34-51) \\
36(21-49)\end{array}$ & $\begin{array}{l}43(32-59) \\
38(19-53)\end{array}$ & $\begin{array}{l}0.1097 \\
0.0564\end{array}$ \\
\hline Duration of infertility (months) & $72(7.0-180.0)$ & $84(12.00-240.0)$ & 0.0761 \\
\hline Primary Infertility \% & 76.2 & 23.8 & \\
\hline Secondary infertility \% & 85 & 15 & \\
\hline BMI $(\mathrm{kg} / \mathrm{m} 2)$ & $26.92 \pm 0.30$ & $27.47 \pm 1.80$ & 0.5492 \\
\hline
\end{tabular}

Data presented as Mean (Range) or Mean \pm SEM

Table 2. Prevalence of various blood borne viruses and their effects on semen quality.

\begin{tabular}{|c|c|c|c|}
\hline Parameters & & $P$ - value & \\
\hline \multicolumn{4}{|l|}{ Source of oocyte } \\
\hline Self & $64.2 \%$ & & \\
\hline Donated & $35.8 \%$ & & \\
\hline \multicolumn{4}{|l|}{ HIV prevalence } \\
\hline Male & $2.2 \%$ & \multirow{2}{*}{$0.7241^{a}$} & \\
\hline Female & $1.3 \%$ & & \\
\hline Total prevalence & $1.7 \%$ & & \\
\hline \multicolumn{4}{|c|}{ Hepatitis B prevalence } \\
\hline Male & $11.8 \%$ & \multirow{2}{*}{$0.0027^{a}$} & \\
\hline Female & $3.9 \%$ & & \\
\hline Total prevalence & $7.9 \%$ & & \\
\hline \multicolumn{4}{|c|}{ Hepatitis C prevalence } \\
\hline Male & $0.4 \%$ & & \\
\hline Female & $0.4 \%$ & & \\
\hline \multirow[t]{2}{*}{ Total prevalence } & $0.4 \%$ & & \\
\hline & BBV Positive & BBV Negative & $P$ - value \\
\hline \multicolumn{4}{|l|}{ Semen quality } \\
\hline Sperm count & $13.6 \pm 2.34$ & $17.7 \pm 0.78$ & 0.0599 \\
\hline$\%$ motility & $26 \pm 2.4$ & $30 \pm 1.0$ & 0.2129 \\
\hline$\%$ Normal forms & $3 \pm 0.3$ & $3 \pm 0.2$ & 0.0617 \\
\hline
\end{tabular}

Data presented as percentages $(n / N)$, mean \pm SEM.

$\mathrm{a}=$ Fisher's exact test was performed.

Significance considered at $P<0.05$

although they were negative during their first attempt. As per standard protocol, all patients who test negative for the Hepatitis B virus are encouraged to receive the vaccination, which was available at the study site. It seems that these two men did not utilize this option. The female partners of these two men tested negative for HBsAg in both cycles, since they received the vaccine after the first testing.

The study did not find any difference between the sperm quality of BBV infected males and their uninfected counterparts. This supports data from Zhou et al. (2011) who also reported no difference in sperm quality between HBV positive and negative males.

There was no significant difference in pregnancy rates between BBV positive couples and their negative counterparts $(36.1 \%$ vs. $34.9 \%, P=0.5000)$. The slight difference in favor of BBV-positive couples could be due to their slightly younger age as compared to their BBV-negative counterparts although again there was no significant difference in their ages $(35.9 \pm 1.0$ vs. $38.2 \pm 0.5$, $P=0.0564$ respectively, Table 1$)$.

We hypothesize that due to the relative high cost of IVF procedures, there is the tendency that those who have no children (primary infertility) will have a greater burden to seek ART services than those with secondary infertility (Table 1).

\section{CONCLUSION}

Access to ARTs is gradually increasing, with about 15 fertility centers in Ghana, although all centers are in the private sector. This current study shows similar BBV prevalence rates in an IVF population and the general population. This underscores the importance of a strict adherence to pre-treatment testing for such viruses, 
Table 3. Effects of HBV on semen quality.

\begin{tabular}{|l|c|c|c|}
\hline & HBV Positive & HBV Negative & $P$ - value \\
\hline Sperm Concentration (million/ml) & $13.5 \pm 2.7$ & $17.7 \pm 0.8$ & 0.0837 \\
\hline Progressive Motility (\%) & $25 \pm 2.7$ & $30 \pm 1.0$ & 0.1583 \\
\hline Normal forms (\%) & $3 \pm 0.3$ & $3 \pm 0.2$ & 0.0838 \\
\hline
\end{tabular}

Data presented as mean \pm SEM.

Table 4. Effects of HIV on semen quality.

\begin{tabular}{|l|c|c|c|}
\hline & HIV Positive & HIV Negative & P - value \\
\hline Count & $9.1 \pm 3.8$ & $17.0 \pm 0.76$ & 0.1383 \\
\hline$\%$ Motility & $26.0 \pm 6.4$ & $29.0 \pm 0.98$ & 0.6264 \\
\hline$\%$ Normal Forms & $2.5 \pm 0.29$ & $3.4 \pm 0.15$ & 0.4068 \\
\hline
\end{tabular}

Data presented as mean \pm SEM.

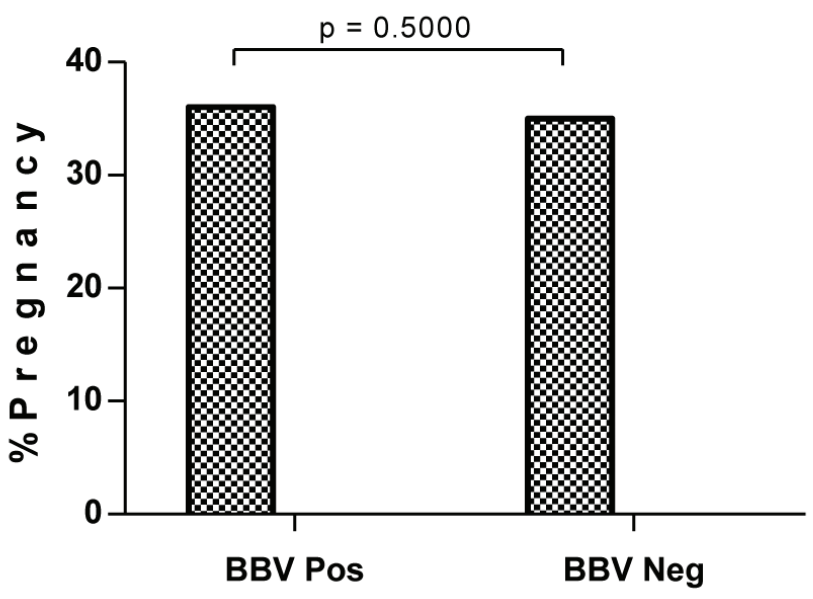

Figure 1. Pregnancy percentage differences by way of BBV infection.

to ensure the safety of personnel and gametes of uninfected patients in these fertility centers. On the basis of viral infectivity, there was no known effect on semen quality. It is, however, noteworthy that these participants were on HAART and these medications could have minimized any adverse effect on semen quality in HIV infected males. A broader study is required to assess semen quality of HIV infected males with and without HAART.

\section{CONFLICT OF INTERESTS}

No conflict of interests have been declared.

\section{Corresponding author:}

Michael B Yakass

Assisted Conception Unit

Lister Hospital \& Fertility Centre

Accra, Ghana

E-mail: michaelyakass@gmail.com

\section{REFERENCES}

Ampofo W, Nii-Trebi N, Ansah J, Abe K, Naito H, Aidoo S, Nuvor V, Brandful J, Yamamoto N, Ofori-Adjei D, Ishikawa $\mathrm{K}$. Prevalence of blood-borne infectious diseases in blood donors in Ghana. J Clin Microbiol. 2002;40:3523-5.

Boivin J, Bunting L, Collins JA, Nygren KG. International estimates of infertility prevalence and treatment-seeking: potential need and demand for infer- tility medical care. Hum Reprod. 2007;22:1506-12.

Brocklehurst $P$, French $R$. The association between maternal HIV infection and perinatal outcome: a systematic review of the literature and meta-analysis. $\mathrm{Br}$ J Obstet Gynaecol. 1998; 105:836-48.

Candotti D, Danso K, Allain JP. Maternofetal transmission of hepatitis B virus genotype E in Ghana, west Africa. J Gen Virol. 2007; 88:2686-95.

Candotti D, Temple J, Sarkodie F, Allain JP. Frequent Recovery and Broad Genotype 2 Diversity Characterize Hepatitis C Virus Infection in Ghana, West Africa. J Virol. 2003; 77:7914-23.

The Commission of the European Communities. Commission directive 2006/17/EC. Implementing Directive 2004/23/EC of the European Parliament and of the Council as regards certain technical requirements for the donation, procurement and testing of human tissues and cells. Official Journal of the European Union.

Cooper TG, Noonan E, von Eckardstein S, Auger J, Baker HW, Behre HM, Haugen TB, Kruger T, Wang C, Mbizvo MT, Vogelsong KM. World Health Organization reference values for human semen characteristics. Hum Reprod Update. $2010 ; 16: 231-45$.

Duda RB, Darko R, Adanu RM, Seffah J, Anarfi JK, Gautam $S$, Hill AG. HIV prevalence and risk factors in women of Accra, Gghana: results from the women's health study of Accra. Am J Trop Med Hyg. 2005; 73:63-6.

Elussein EA, Magid YM, Omer MM, Adam I. Clinical patterns and major causes of infertility among Sudanese couples. Trop Doct. 2008;38:243-4.

Ghana Health Service. Guidelines for Antiretroviral therapy in Ghana. 2008. Available at: http://www.who.int/hiv/ pub/guidelines/ghana_art.pdf?ua $=1$

Glynn JR, Buvé A, Caraël M, Kahindo M, Macauley IB, Musonda RM, Jungmann E, Tembo F, Zekeng L. Decreased fertility among HIV-1-infected women attending antenatal clinics in three African cities. J Acquir Immune Defic Syndr. $2000 ; 25: 345-52$.

Huang JM, Huang TH, Qiu HY, Fang XW, Zhuang TG, Liu $H X$, Wang $Y H$, Deng LZ, Qiu JW. Effects of hepatitis B virus infection on human sperm chromosomes. World J Gastroenterol. 2003;9:736-40. 
Huang JM, Huang TH, Qiu HY, Fang XW, Zhuang TG, Qiu JW. Studies on the integration of hepatitis $B$ virus DNA sequence in human sperm chromosomes. Asian J Androl. $2002 ; 4: 209-12$.

Larsen U, Masenga G, Mlay J. Infertility in a community and clinic-based sample of couples in Moshi, Northern Tanzania. East Afr Med J. 2006;83:10-7.

Lesourd F, Izopet J, Mervan C, Payen JL, Sandres K, Monrozies $\mathrm{X}$, Parinaud J. Transmissions of hepatitis $\mathrm{C}$ virus during the ancillary procedures for assisted conception. Hum Reprod. 2000;15:1083-5.

Lorusso F, Palmisano M, Chironna M, Vacca M, Masciandaro P, Bassi E, Selvaggi Luigi L, Depalo R. Impact of chronic viral diseases on semen parameters. Andrologia. 2010;42:121-6.

Magli MC, Van den Abbeel E, Lundin K, Royere D, Van der Elst J, Gianaroli L; Committee of the Special Interest Group on Embryology. Revised guidelines for good practice in IVF laboratories. Hum Reprod. 2008; 23:1253-62.

Ombelet W, Cooke I, Dyer S, Serour G, Devroey P. Infertility and the provision of infertility medical services in developing countries. Hum Reprod Update. 2008;14:605-21.

Pirwany IR, Phillips S, Kelly S, Buckett W, Tan SL. Reproductive performance of couples discordant for hepatitis $B$ and C following IVF treatment. J Assist Reprod Genet. $2004 ; 21: 157-61$
Practice Committee of American Society for Reproductive Medicine; Practice Committee of Society for Assisted Reproductive Technology. Revised guidelines for human embryology and andrology laboratories. Fertil Steril. 2008; 90: S45-59.

Rouchou B. Consequences of infertility in developing countries. Perspect Public Health. 2013; 133:174-9

Savasi V, Mandia L, Laoreti A, Cetin I. Reproductive assistance in HIV serodiscordant couples. Hum Reprod Update. 2013;19:136-50

WHO. Country factsheet. 2015. Available at: http://aidsinfo.unaids.org/. Accessed: 25/08/2015.

Zafer M, Horvath H, Mmeje O, van der Poel S, Semprini AE, Rutherford G, Brown J. Effectiveness of semen washing to prevent human immunodeficiency virus (HIV) transmission and assist pregnancy in HIV-discordant couples: a systematic review and meta-analysis. Fertil Steril. 2016;105: 645-55.

Zamora MJ, Obradors A, Woodward B, Vernaeve V, Vassena $\mathrm{R}$. Semen residual viral load and reproductive outcomes in HIV-infected men undergoing ICSI after extended semen preparation. Reprod Biomed Online. 2016;32:584-90.

Zhou XP, Hu XL, Zhu YM, Qu F, Sun SJ, Qian YL. Comparison of semen quality and outcome of assisted reproductive techniques in Chinese men with and without hepatitis B. Asian J Androl. 2011;13:465-9. 